\title{
Editorial. El sistema mediático español ante el reto de la desinformación
}

\author{
Javier Marzal-Felici \\ Universitat Jaume I \\ Andreu Casero-Ripollés \\ Universitat Jaume I
}

\section{Referencia de este artículo}

Marzal-Felici, Javier y Casero-Ripollés, Andreu (2022). Editorial no 23. El sistema mediático ante el reto de la desinformación. En: adComunica. Revista Científica de Estrategias, Tendencias e Innovación en Comunicación, $\mathrm{n}^{0}$ 23. Castellón: Universitat Jaume I, 11-15. DOI: http://dx.doi.org/10.6035/adcomunica.6440.

\section{La relevancia de los medios de comunicación en la sociedad de la información}

Hace unas pocas semanas, los días 4 y 5 de noviembre de 2021, tuvimos la oportunidad de celebrar en Castellón una nueva edición del Congreso de Comunicación Local, el ComLoc 2021, en su decimosexta edición, cuya temática ha girado en torno a los «Medios de comunicación públicos, ciudadanía e influencia digital en la era de la desinformación». Esta nueva edición del ComLoc fue muy gratificante en la medida en que nos permitió volver a celebrar un acto académico presencial, tras más de año y medio de pandemia, un hecho que valoraron muy positivamente tanto el alumnado como los miembros de la comunidad académica y profesional que participaron en esta actividad científica.

El número 21 de la revista adComunica, de enero de 2021, dedicaba el monográfico a los «Medios de comunicación públicos y participación ciudadana», mientras que el número 22, de julio de 2021, hacía énfasis en el importante papel que están jugando los medios de comunicación, en especial, los medios públicos, para ayudar a desvelar la importancia del análisis de las imágenes en la era de las fake 
news. Así pues, este es el tercer número que versa, directa e indirectamente, sobre la temática de los medios de comunicación -públicos y privados- en la era de la desinformación. Esto se debe a la excepcionalidad de los tiempos que estamos viviendo, marcados por el protagonismo de los medios de comunicación, por un lado, y de la desinformación, por otro.

El monográfico de este número, titulado «La era de la desinformación global: diagnósticos y respuestas», ha sido coordinado por los profesores Luis Bouza García, profesor de Ciencia Política y Relaciones Internacionales en la Universidad Autónoma de Madrid, y Jorge Tuñón Navarro, profesor de Periodismo de la Universidad Carlos III de Madrid, a quienes agradecemos su generosa colaboración.

La crisis sanitaria por el Coronavirus nos ha permitido tomar conciencia de que los medios de comunicación públicos, en especial, pero también los medios privados, son esenciales en nuestra sociedad. Esta pandemia ha desarrollado, en paralelo a la crisis sanitaria, una infodemia, que ha multiplicado exponencialmente la circulación de noticias falsas. En este contexto, el sistema de medios está sufriendo importantes transformaciones debido a la convergencia digital, la expansión de las redes sociales, la acelerada concentración de medios vinculada al auge de los GAFAM -Google, Amazon, Facebook, Apple, Microsoft- y el auge del consumo online como consecuencia de la universalización de las pantallas y de las plataformas digitales.

Debemos ser conscientes de que en este contexto de expansión de «mediatizaciones ubicuas», como afirman José Manuel Pérez Tornero (2020) y Juan Miguel Aguado (2020), han calado con mucha fuerza dos noticias falsas extraordinariamente peligrosas: por un lado, la idea de que los medios públicos no son necesarios; por otro, la idea de que el espacio mediático, por definición, de naturaleza pública, no debe estar sujeto a vigilancia y regulación por una autoridad independiente como los Consejos Audiovisuales. Para combatir estos argumentos es indispensable que, tanto los medios de comunicación públicos como las autoridades reguladoras, deben ser gestionadas con la máxima independencia posible del poder político, si bien han de estar sometidos a la rendición de cuentas ante nuestras instituciones públicas y la sociedad, como es lógico. Así debe exigirse en el nuevo paradigma de la gobernanza y de la transparencia que han de cumplir todas las administraciones públicas.

En estos últimos años, estamos viendo que el actual avance de la sociedad digital -a través del desarrollo de las redes sociales y de la plataformización de la información y del entretenimiento- está sirviendo, en especial, para multiplicar la expansión de los populismos y de la desinformación. No creemos exagerado señalar que el futuro de la democracia se juega muy especialmente en el espacio mediático. De ahí que manifestemos reiteradamente nuestra preocupación por la independencia de los medios públicos, que necesitan contar con los recursos financieros suficientes 
para desarrollar su actividad adecuadamente. Y cada vez parece más claro que la alfabetización mediática es una línea de acción necesaria que debe ir paralela al desarrollo de nuestro ecosistema mediático, en el que está en juego el desarrollo de las industrias creativas y culturales que son de especial relevancia en cualquier economía avanzada.

\section{La alfabetización mediática como estrategia para luchar contra la desinformación: la creación de la Cátedra RTVE - UJI}

Si en el número 22 de adComunica, de julio de 2021, celebrábamos la creación del Consejo Audiovisual de la Comunidad Valenciana, que ya es una realidad en el inicio de 2022, no podemos dejar de compartir con nuestros lectores y con la comunidad científica, la reciente noticia de la creación de la Cátedra RTVE-UJI sobre "Cultura audiovisual y alfabetización mediática», cuyo convenio fue firmado el 4 de enero de 2022, y que comenzará su andadura en los próximos meses. El proyecto de Investigación en el que venimos trabajando desde 2019 «Participación ciudadana y medios de comunicación públicos. Análisis de experiencias de cocreación audiovisual en España y Europa (PARCICOM)», proponía la puesta en marcha de una experiencia de cocreación que pudiera servir para conocer cómo es desde dentro una producción de estas características, con una temática centrada en la alfabetización mediática. En realidad, nuestro interés por la participación en los medios y, muy especialmente por la cocreación como forma de participación más completa y desarrollada, coincide con la de numerosos profesionales y expertos a nivel internacional en los últimos años. En este sentido, cabe destacar el Informe EBU Youth Report. What Works?, desarrollado por la Unión Europea de Radiodifusión en 2020, que presenta el estudio y análisis de 60 experiencias de cocreación en géneros audiovisuales como informativos, sociedad y entretenimiento educativo, comedia y tele-realidad, radio y sonido, ficción y juegos y deportes. Este estudio pone de manifiesto la necesidad de apostar por el desarrollo de producciones en las que se incentive la participación de diferentes colectivos ciudadanos, como vía para empoderar a la ciudadanía y para reforzar el papel de los medios de comunicación públicos en el contexto actual. Hablamos de producciones que cumplen, en general, una función de servicio público y que no buscan una rentabilidad económica, sino social, por lo que no entran en competencia con los medios privados.

La propuesta de creación de esta Cátedra RTVE en la Universitat Jaume I nos ofrece la posibilidad de construir un marco idóneo para hacer posible un avance significativo en el campo de la alfabetización mediática. Para ello, nos proponemos crear un espacio colaborativo entre administraciones educativas, universidades, centros de enseñanza, estudiantes de los niveles educativos implicados y la propia Corporación RTVE. Para nosotros, es importante la participación en esta experiencia de profesores y expertos de las universidades, de profesores y expertos del 
Ministerio de Educación y de la Conselleria de Educación y de «profesores especialistas» de los Centros de Formación de Profesores (CEFIRE). Además, nos parece también relevante la participación de estudiantes universitarios, de secundaria y bachillerato que puedan incorporarse progresivamente a este proyecto, cuyo recorrido temporal es necesariamente largo. Y no nos olvidamos de los profesionales de la comunicación y de las corporaciones públicas de ámbito autonómico, que pueden jugar un papel destacable en esta experiencia.

En una primera etapa, nos hemos propuesto desarrollar una serie de materiales en soporte videográfico, acompañados de documentos escritos, que puedan servir de ayuda a la comunidad educativa -estudiantes, profesores y familias- para facilitar el aprendizaje de los principales contenidos previstos en el curriculum oficial de la asignatura "Cultura Audiovisual II», que se imparte en el segundo curso del Bachillerato Artístico, y es asignatura optativa en las pruebas de Evaluación para el Acceso a la Universidad (EvAU) desde el curso 2016-17, mediante de la producción de vídeo cápsulas breves y sencillas de entender.

No deja de ser paradójico que en estos momentos el Ministerio de Educación haya realizado una propuesta de modificación del currículum del Bachillerato de Artes, en la que se prevé la eliminación de la asignatura "Cultura Audiovisual II", una novedad que ha sorprendido a la comunidad científica del campo de la comunicación y que ha provocado una reacción unánime que se explica con detalle en una tribuna publicada por el periódico El País el pasado 2 de diciembre de 2021. En cualquier caso, más allá de lo que finalmente pueda ocurrir en el campo de la educación reglada, el objetivo de esta Cátedra RTVE - UJI es promover la alfabetización mediática, que pueda ser útil a docentes, estudiantes y familias, con independencia del nivel educativo de que se trate, en la línea de lo que vienen realizando desde hace años las importantes corporaciones públicas de medios como France Télévisions, BBC, RAI, etc. (Marzal-Felici, Soler-Campillo, López-Olano y Loriguillo-López, 2022).

\section{Agradecimientos y créditos}

Queremos dejar constancia de que este número de la revista adComunica ha recibido el apoyo de los Proyectos de Investigación «Participación ciudadana y medios de comunicación públicos. Análisis de experiencias de co-creación audiovisual en España y en Europa (PARCICOM)» (código RTI2018-093649-B-I00), bajo la dirección de Javier Marzal Felici, financiado por la Convocatoria 2018 de Proyectos de $\mathrm{I}+\mathrm{D}+\mathrm{I}$ «Retos Investigación», del Programa Estatal de I+D+i orientada a los Retos de la Sociedad, Ministerio de Ciencia, Innovación y Universidades, para el periodo 2019-2021, y del Proyecto de investigación «Influencers en la comunicación política en España: análisis de las relaciones entre lideres de opinión 2.0, medios, partidos, instituciones y audiencias en el entorno digital» (código CSO2017-88620-P), 
bajo la dirección de Andreu Casero-Ripollés, financiado por la Convocatoria 2017 de Proyectos de I+D+I «Excelencia», del Programa Estatal de I+D+i, Ministerio de Ciencia, Innovación y Universidades, para el periodo 2018-2020.

Como ya es habitual, no podemos finalizar nuestro editorial sin dejar de agradecer el compromiso y generosidad de los investigadores, revisores y profesionales, y del equipo de dirección de la revista adComunica que han participado en este número, de los coordinadores de las secciones y, de nuestra comunidad científica, que contribuyen a fortalecer este proyecto editorial.

\section{Referencias}

Aguado, Juan Miguel (2020). Mediaciones ubicuas. Ecosistema móvil, gestión de identidad y nuevo espacio público. Barcelona: Gedisa.

European Broadcasting Union (2020). Youth Report. What Works?. Ginebra: European Broadcasting Union. Consultado el 26 de enero de 2022 en https://www. ebu.ch/publications/strategic/membersonly/report/youth-report-what-works.

Marzal-Felici, Javier; Soler-Campillo, Maria; López-Olano, Carlos y LoriguilloLópez, Antonio (2022). Análisis comparado de experiencias de cocreación sobre alfabetización mediática en algunos medios públicos en Europa. La propuesta participativa de educomunicación "La mirada cautiva" para los medios públicos de España. En: Javier Marzal-Felici, José Moriano, César Fieiras-Ceide, Martín Vaz-Álvarez y Antonio Loriguillo-López (Eds.), Participación ciudadana y medios de comunicación públicos 2. Experiencias de cocreación en España y en Europa. Valencia: Tirant Lo Blanch (en prensa).

Pérez Tornero, José Manuel (2020). La gran mediatización. El tsunami que expropia nuestras vidas. Del confinamiento digital a la sociedad de la distancia. Barcelona: UOCPress Comunicación. 